\title{
PK/PD analysis of biapenem in patients undergoing continuous hemodiafiltration
}

\author{
Gaku Akashita 1,2, Yuto Hosaka ${ }^{2,3}$, Toru Noda ${ }^{4}$, Kazuya Isoda ${ }^{2}$, Tsutomu Shimada ${ }^{1,2}$, Kazuki Sawamoto ${ }^{1,2}$, \\ Ken-ichi Miyamoto ${ }^{1,2}$, Takumi Taniguchi ${ }^{4}$ and Yoshimichi Sai ${ }^{1,2^{*}}$
}

\begin{abstract}
Background: Continuous hemodiafiltration (CHDF) is used as renal replacement therapy for critically ill patients with renal failure, and to treat hypercytokinemia. Since CHDF also clears therapeutic agents, drug pharmacokinetics (PK) should be dependent upon CHDF conditions. Although the antibiotic biapenem (BIPM) is used in patients undergoing CHDF, the optimal therapeutic regimen in such patients has not been fully clarified. In this study, we investigated the PK of BIPM in patients with various levels of renal function undergoing CHDF with polysulfone (PS) membrane, and used PK models to identify the optimal administration regimen.
\end{abstract}

Methods: BIPM (300 mg) was administered by infusion in patients undergoing CHDF $(n=7)$. Blood and filtrate-dialysate were collected for compartment and non-compartment analysis.

Results: The sieving coefficient of PS membrane was $1.00 \pm 0.06$ (mean \pm S.D., $n=7$ ), and CHDF clearance of BIPM was found to be the sum of the dialysate flow rate $\left(Q_{D}\right)$ and filtrate flow rate $\left(Q_{F}\right)$. Non-CHDF clearance showed inter-individual variability $(4.82 \pm 2.48 \mathrm{~L} / \mathrm{h})$, depending on residual renal function and non-renal clearance. Based on the average PK parameters obtained with a compartmental model, maximal kill end point (over $40 \% \mathrm{~T}>\mathrm{MIC}_{4} \mathrm{\mu g} / \mathrm{mL}$ ) was achieved with regimens of $300 \mathrm{mg}$ every 6 h, $300 \mathrm{mg}$ every $8 \mathrm{~h}$, and $600 \mathrm{mg}$ every $12 \mathrm{~h}$. Monte Carlo simulation indicated that $300 \mathrm{mg}$ infusion for $1 \mathrm{~h}$ every $6 \mathrm{~h}$ was optimal, and the probability of target attainment at $\mathrm{MIC}_{2} \mu \mathrm{g} / \mathrm{mL}$ was $90.2 \%$.

Conclusions: Our results establish the optimal regimen of BIPM in patients with various levels of renal function undergoing CHDF with a PS membrane.

Keywords: Biapenem, Continuous hemodiafiltration, Pharmacokinetics, Monte Carlo simulation, PK/PD breakpoint

\section{Background}

Continuous hemodiafiltration (CHDF) is a blood purification method that provides alternative functionality for patients with kidney failure. It removes a wide range of compounds, ranging from low-molecular-weight products such as urea nitrogen and creatinine to mediummolecular-weight compounds such as $\beta-2$ microglobulin and cytokines $[1,2]$. Therefore, $\mathrm{CHDF}$ is widely used in intensive care units to treat patients with unstable hemodynamic pathologies, including acute pancreatitis,

\footnotetext{
* Correspondence: sai-ys@staff.kanazawa-u.ac.jp

'Department of Medicinal Informatics, Graduate School of Medical Sciences,

Kanazawa University, 13-1 Takara-machi, Kanazawa 920-8640, Japan

${ }^{2}$ Department of Hospital Pharmacy, University Hospital, Kanazawa University,

13-1 Takara-machi, Kanazawa 920-8641, Japan

Full list of author information is available at the end of the article
}

fulminant hepatitis, and acute renal failure, as well as to remove cytokines in sepsis patients, even if they have normal renal function [3-6]. Since the pharmacokinetics (PK) of medications may be affected by elimination through dialysis and filtration during CHDF therapy, it is necessary to select an appropriate administration regimen (timing, dose amount, and dose rate) depending upon the conditions of CHDF $[7,8]$. It has also been reported that drug clearance varies depending on the material of the dialysis membrane [9], and cytokine clearance is also dependent on the dialysis membrane material [2].

Biapenem (BIPM) is a carbapenem antibacterial agent with broad-spectrum, potent activity against Gram-

(c) 2015 Akashita et al. Open Access This article is distributed under the terms of the Creative Commons Attribution 4.0 International License (http://creativecommons.org/licenses/by/4.0/), which permits unrestricted use, distribution, and reproduction in any medium, provided you give appropriate credit to the original author(s) and the source, provide a link to the Creative Commons license, and indicate if changes were made. The Creative Commons Public Domain Dedication waiver (http://creativecommons.org/publicdomain/zero/1.0/) applies to the data made available in this article, unless otherwise stated. 
positive, Gram-negative, and anaerobic bacteria [10]. It is not cleaved by dehydropeptidase-1 (DHP-1), unlike other penem antibiotics such as panipenem and imipenem, and can be used as a single agent without the need for formulation of a nephrotoxicity-reducing agent or DHP-1 inhibitor [11-13]. Carbapenems are classified as timedependent antibiotics, and the clinical outcome is closely correlated with the duration for which the drug concentration remains at or above the minimum inhibitory concentration (MIC); the time above the MIC ( $>$ > MIC) needs to be over 20 and $40 \%$ of the dosing interval to achieve stasis and maximal kill as end points, respectively $[14,15]$. For carbapenem antibiotics, sensitive MIC and intermediate MIC are defined as $\geq 4 \mu \mathrm{g} / \mathrm{mL}$ and $\geq 8 \mu \mathrm{g} / \mathrm{mL}$, respectively [16]. To obtain optimum effects of BIPM, we need to predict $\mathrm{T}>\mathrm{MIC}$ from the PK parameters of BIPM. BIPM is mainly excreted from the kidneys, and clearance of BIPM in patients with renal failure is decreased to $2.62 \mathrm{~L} / \mathrm{h}$, i.e., approximately $20 \%$ of that of healthy adults [17]. CHDF also alters the clearance of BIPM, and Ikawa et al. have reported on PK modeling and dosage adaptation of BIPM during CHDF with a polymethyl methacrylate (PMMA) membrane in patients with renal failure [18]. The PK of single BIPM administration was calculated using multi-compartment models, and it was found that the dose amount and dosing interval were important factors determining the value of $\%$ of $\mathrm{T}>$ MIC. However, their models were applicable only to patients with renal failure. Since CHDF is also used for patients with various levels of renal function, models that take account of this are required. Furthermore, the effects of other types of filter membrane in CHDF should also be considered.

In the present study, we developed non-compartmental and compartmental models for repeated BIPM treatment in patients with various levels of renal function undergoing CHDF with a polysulfone (PS) membrane, and examined the optimum treatment regimen by means of Monte Carlo simulation.

\section{Methods}

\section{Patients}

This study was approved by the Clinical Research Ethics Committee of Kanazawa University Hospital (2011-052). Adult patients older than 20 years who were receiving CHDF for acute renal failure or removal of cytokines, and who were prescribed BIPM to treat infection were eligible. Prior to the start of the investigation, informed consent was obtained in writing from each participant or his/her relatives. We excluded patients taking sodium valproate, or with a history of hypersensitivity to carbapenems or fourth-generation cephems, or with contraindications for carbapenems or fourth-generation cephems, or with a history of epilepsy or central nervous system damage. Seven patients (5 males, 2 females) were enrolled. Demographic and medical characteristics of each patient are summarized in Table 1. The glomerular filtration rate (GFR) of each patient was evaluated before CHDF application.

\section{CHDF}

In the present study, a PS hemofilter with a membrane surface area of $1.3 \mathrm{~m}^{2}$ (EXCELFLO ${ }^{\circ}$ AEF-13, Asahi Kasei Medical Co., Japan) was used for hemopurification. CHDF was performed basically with a blood flow rate $\left(\mathrm{Q}_{\mathrm{B}}\right)$ of $80 \mathrm{~mL} / \mathrm{min}$, dialysate flow rate $\left(\mathrm{Q}_{\mathrm{D}}\right)$ of $500 \mathrm{~mL} / \mathrm{h}$, substitution flow rate $\left(\mathrm{Q}_{\mathrm{S}}\right)$ of $500 \mathrm{~mL} / \mathrm{h}$, and filtration flow rate $\left(\mathrm{Q}_{\mathrm{F}}\right)$ of $1000 \mathrm{~mL} / \mathrm{h}$, and was regulated appropriately based on each patient's status. Sublood-BS ${ }^{\oplus}$ (Fuso Pharmacy, Inc., Japan) was used as a dialysate and also served as a substitution fluid for post-dilutional infusion. During CHDF, nafamostat mesylate was serially administered at a rate of approximately $20 \mathrm{mg} / \mathrm{h}$ to avoid coagulation within the circuit.

\section{BIPM administration and collection of blood and filtrate-dialysate samples}

Three hundred milligrams of BIPM (Omegacin ${ }^{\bullet} 0.3 \mathrm{~g}$, Meiji Seika Pharma Co., Japan) was administered by intravenous drip infusion for 0.5 or $1 \mathrm{~h}$ at 6,8 , or $12 \mathrm{~h}$ intervals

Table 1 Patient characteristics

\begin{tabular}{|c|c|c|c|c|c|c|c|c|c|}
\hline Patient & Sex & Age (years) & $\mathrm{Ht}(\mathrm{cm})$ & BW (kg) & BSA $\left(m^{2}\right)$ & Infusion Interval (hr) & Dose (mg) & Infusion time (hr) & GFR (mL/min/body) \\
\hline A & M & 64 & 167 & 95.1 & 2.03 & 12 & 300 & 1 & 20.4 \\
\hline B & M & 70 & 157 & 53.1 & 1.50 & 8 & 300 & 1 & 17.0 \\
\hline C & $\mathrm{F}$ & 33 & 160 & 57.5 & 1.61 & 12 & 300 & 1 & 15.8 \\
\hline D & M & 65 & 166 & 65.0 & 1.70 & 6 & 300 & 1 & 58.8 \\
\hline$E$ & M & 75 & 162 & 47.8 & 1.45 & 8 & 300 & 1 & 31.0 \\
\hline $\mathrm{F}$ & M & 55 & 164 & 64.8 & 1.69 & 6 & 300 & 0.5 & 63.3 \\
\hline G & $\mathrm{F}$ & 80 & 145 & 66.7 & 1.60 & 8 & 300 & 0.5 & 8.4 \\
\hline Mean & & 63.1 & 160.1 & 64.3 & 1.65 & & & & 30.7 \\
\hline SD & & 15.6 & 7.5 & 15.3 & 0.19 & & & & 21.9 \\
\hline
\end{tabular}

Ht height; $B W$ body weight; BSA body surface area; GFR glomerular filtration rate (value before CHDF); SD standard deviation 
(Table 1). Blood samples were taken from the blood access port in the extracorporeal circuit proximal to the filter before dosing, at $0,0.5,1,2$, and $4 \mathrm{~h}$ after infusion, and just before the next infusion. Filtrate-dialysate (FD) samples were simultaneously collected from the filtrate tube to determine the sieving coefficient (SC) and CHDF clearance. After collection, each blood sample was centrifuged immediately. The plasma and supernatants of FD samples were immediately frozen at $-80{ }^{\circ} \mathrm{C}$ and stored until assay.

\section{Method of quantitative analysis of BIPM}

Quantitative analysis of BIPM in plasma and FD was performed using high-performance liquid chromatography (HPLC) [18]. Briefly, plasma or FD sample $(200 \mu \mathrm{L})$ was mixed with $200 \mu \mathrm{L}$ of $1 \mathrm{M}$ 3-morpholinopropane-1-sulfonic acid buffer. An aliquot $(300 \mu \mathrm{L})$ was transferred to an ultrafiltration device (Nanosep ${ }^{\circ}$ Centrifugal Devices $10 \mathrm{~K}$, Pall Life Sciences, USA), and centrifuged at 15,000 g for $15 \mathrm{~min}$ at $15^{\circ} \mathrm{C}$. An aliquot of the ultrafiltered solution $(20 \mu \mathrm{L})$ was injected into an HPLC system (Prominence, Shimadzu Co., Japan) equipped with an Octadecyl silica column (Shim-pack CLC-ODS $5 \mu \mathrm{m}$ (150 x 6 i.d.), Shimadzu Co., Japan) and a UV detector (232 nm). The mobile phase of $1.5 \%$ acetonitrile and $98.5 \% 0.1 \mathrm{M}$ sodium acetate buffer ( $\mathrm{pH}$ 4.6) was delivered isocratically at a flow rate of $1.0 \mathrm{~mL} / \mathrm{min}$. The auto-sampler temperature was set at $4{ }^{\circ} \mathrm{C}$, and the column temperature at $40{ }^{\circ} \mathrm{C}$. The calibration curve was linear from 0.1 to $50 \mu \mathrm{g} / \mathrm{mL}$, and the lower limit of detection was $0.1 \mu \mathrm{g} / \mathrm{mL}$.

\section{Calculation of PK parameters of BIPM}

Non-compartmental and compartmental analyses were performed using PK analysis software: Numeric Analysis Program for Pharmacokinetics (Napp) ver. 2.31 (Department of Pharmacy, the University of Tokyo Hospital). The area under the BIPM concentration-time curve (AUC) was calculated based on the logarithmic trapezoidal rule. The $\mathrm{SC}$ was determined as $\mathrm{AUC}_{\mathrm{FD}} / \mathrm{AUC}_{\text {plasma }}$. The $\mathrm{AUC}$ after first administration was calculated from $0 \mathrm{~h}$ to infinity, and subsequent AUCs were estimated from $0 \mathrm{~h}$ to the start of the next infusion interval, since the half-life of BIPM in healthy persons is $1 \mathrm{~h}$ [19]. The differential equations for mass balances were as follows (Fig. 1):

$$
\begin{aligned}
& \frac{d X_{1}}{d t}=R_{\text {inf }}-\left(k_{10}+k_{12}+k_{13}\right) \cdot X_{1}+k_{21} \cdot X_{2} \\
& \frac{d X_{2}}{d t}=k_{12} \cdot X_{1}-k_{21} \cdot X_{2} \\
& \frac{d X_{3}}{d t}=k_{13} \cdot X_{1}-k_{30} \cdot X_{3}
\end{aligned}
$$

where $X_{1}, X_{2}$ and $X_{3}$ are the amounts of drug $(\mathrm{mg})$ in the central, peripheral and hemofilter compartment,

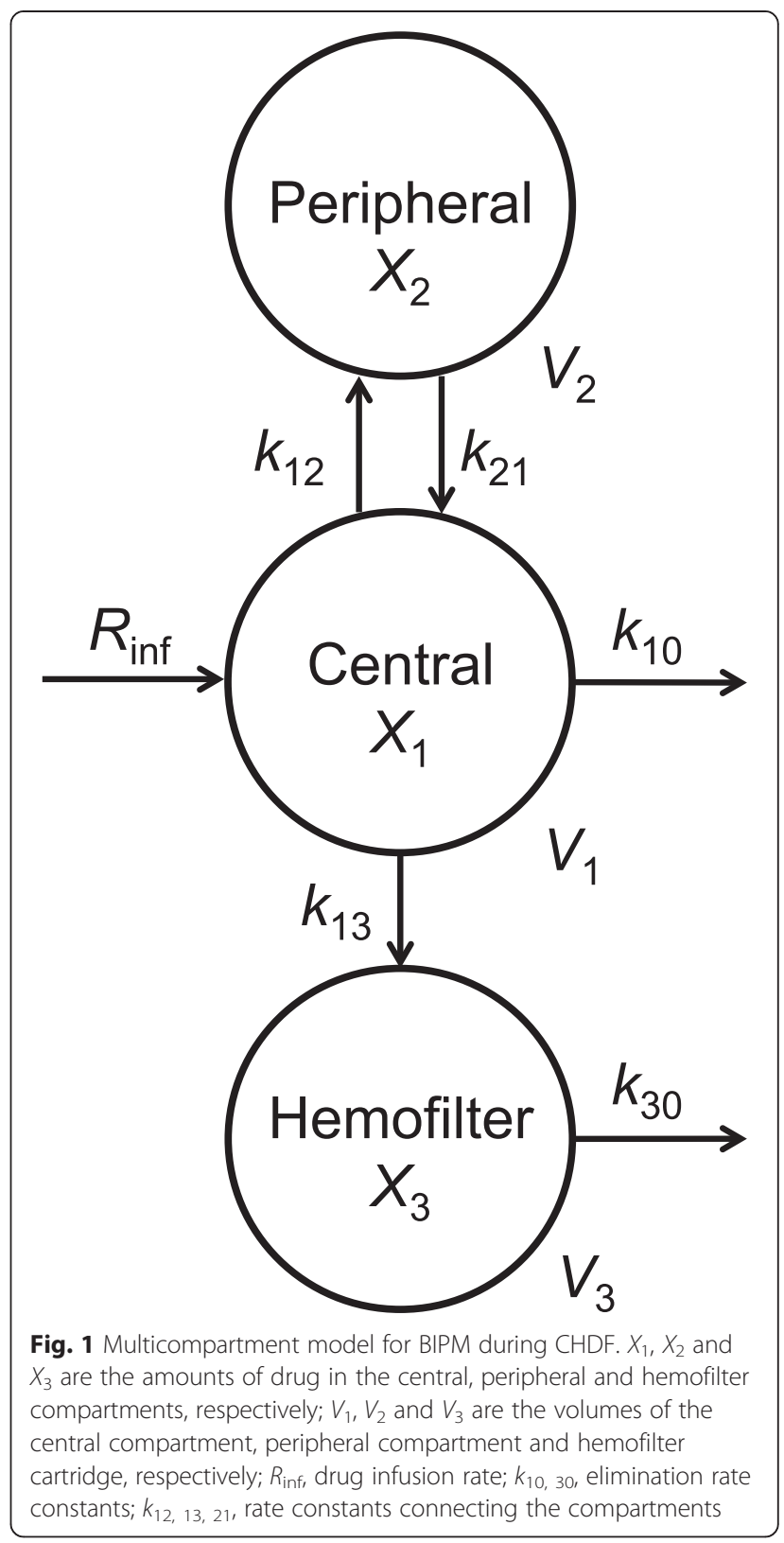

respectively; $R_{\text {inf }}$ is the drug infusion rate $(\mathrm{mg} / \mathrm{hr}) ; k_{10}$ and $k_{30}$ are the elimination rate constant $\left(\mathrm{hr}^{-1}\right)$ from the central compartment and the hemofilter compartment, respectively; $k_{12}$ and $k_{21}$ are the intercompartmental transfer rate constants $\left(\mathrm{hr}^{-1}\right) ; k_{13}$ is transfer rate constant $\left(\mathrm{hr}^{-1}\right)$ from the central compartment to the hemofilter compartment.

These equations were used to obtain the following formulas for the drug concentrations $(\mu \mathrm{g} / \mathrm{mL})$ in the central compartment $\left(\mathrm{C}_{1}\right)$ and $\mathrm{FD}\left(\mathrm{C}_{3}\right)$ at time $\mathrm{t}(\mathrm{hr})$ during and after administration in the steady state:

(i) $0 \leqq t \leqq T_{\text {inf }}$ 


$$
\begin{aligned}
C_{1}=\frac{R_{i n f}}{V_{1}}\left\{\frac{(}{\alpha(\beta-\alpha)}\left(e^{\alpha \cdot T_{i n f}}-1\right)\left(\frac{e^{-\alpha \cdot \tau}}{1-e^{-\alpha \cdot \tau}}\right) e^{-\alpha \cdot t}\right. \\
+\frac{\left(k_{21}-\beta\right)}{\beta(\alpha-\beta)}\left(e^{\beta \cdot T_{i n f}}-1\right)\left(\frac{e^{-\beta \cdot \tau}}{1-e^{-\beta \cdot \tau}}\right) e^{-\beta \cdot t} \\
\left.+\frac{\left(k_{21}-\alpha\right)}{\alpha(\beta-\alpha)}\left(1-e^{-\alpha \cdot t}\right)+\frac{\left(k_{21}-\beta\right)}{\beta(\alpha-\beta)}\left(1-e^{-\beta \cdot t}\right)\right\} \\
C_{3}=\frac{R_{\text {inf }} \cdot k_{13}}{V_{3}}\left\{\frac { ( k _ { 2 1 } - \alpha ) } { \alpha ( \beta - \alpha ) ( k _ { 3 0 } - \alpha ) } \left(e^{\left.\alpha \cdot T_{i n f}-1\right)}\left(\frac{e^{-\alpha \cdot \tau}}{1-e^{-\alpha \cdot \tau}}\right) e^{-\alpha \cdot t}\right.\right. \\
+\frac{\left(k_{21}-\beta\right)}{\beta(\alpha-\beta)\left(k_{30}-\beta\right)}\left(e^{\beta \cdot T_{i n f}}-1\right)\left(\frac{e^{-\beta \cdot \tau}}{1-e^{-\beta \cdot \tau}}\right) e^{-\beta \cdot t} \\
+\frac{\left(k_{21}-k_{30}\right)}{k_{30}\left(\alpha-k_{30}\right)\left(\beta-k_{30}\right)}\left(e^{\left.k_{30} \cdot T_{i n f}-1\right)}\left(\frac{e^{-k_{30} \cdot \tau}}{1-e^{-k_{30} \cdot \tau}}\right) e^{-k_{30} \cdot t}\right. \\
+\frac{\left(k_{21}-\alpha\right)}{\alpha(\beta-\alpha)\left(k_{30}-\alpha\right)}\left(1-e^{-\alpha \cdot t}\right)+\frac{\left(k_{21}-\beta\right)}{\beta(\alpha-\beta)\left(k_{30}-\beta\right)} \\
\left.\times\left(1-e^{-\beta \cdot t}\right)+\frac{\left(k_{21}-k_{30}\right)}{k_{30}\left(\alpha-k_{30}\right)\left(\beta-k_{30}\right)}\left(1-e^{-k_{30} \cdot t}\right)\right\}
\end{aligned}
$$

(ii) $\mathrm{t}>\mathrm{T}_{\mathrm{inf}}$

$$
\begin{aligned}
C_{1}=\frac{R_{\text {inf }}}{V_{1}}\left\{\frac{(}{\alpha(\beta-\alpha)}\left(e^{\alpha \cdot T_{\text {inf }}}-1\right)\left(\frac{1}{1-e^{-\alpha \cdot \tau}}\right) e^{-\alpha \cdot t}\right. \\
\left.+\frac{\left(k_{21}-\beta\right)}{\beta(\alpha-\beta)}\left(e^{\beta \cdot T_{\text {inf }}}-1\right)\left(\frac{1}{1-e^{-\beta \cdot \tau}}\right) e^{-\beta \cdot t}\right\} \\
C_{3}=\frac{R_{\text {inf }} \cdot k_{13}}{V_{3}}\left\{\frac{\left(k_{21}-\alpha\right)}{\alpha(\beta-\alpha)\left(k_{30}-\alpha\right)}\left(e^{\alpha \cdot T_{\text {inf }}}-1\right)\left(\frac{1}{1-e^{-\alpha \cdot \tau}}\right) e^{-\alpha \cdot t}\right. \\
+\frac{\left(k_{21}-\beta\right)}{\beta(\alpha-\beta)\left(k_{30}-\beta\right)}\left(e^{\beta \cdot T_{i n f}}-1\right)\left(\frac{1}{1-e^{-\beta \cdot \tau}}\right) e^{-\beta \cdot t} \\
\left.+\frac{\left(k_{21}-k_{30}\right)}{k_{30}\left(\alpha-k_{30}\right)\left(\beta-k_{30}\right)}\left(e^{k_{30} \cdot T_{\text {inf }}}-1\right)\left(\frac{1}{1-e^{-k_{30} \cdot \tau}}\right) e^{-k_{30} \cdot t}\right\}
\end{aligned}
$$

Where $\mathrm{T}_{\text {inf }}$ is the drug infusion time (hr); $\mathrm{T}$ is the inter-dose interval (hr); $V_{1}$ is the volume of distribution of the central compartment; $V_{3}$ is the blood volume of the hemofilter cartridge; and $\alpha$ and $\beta$ are macro rate constants $\left(\mathrm{hr}^{-1}\right)$ expressed as $\alpha+\beta=k_{12}+k_{21}+k_{10}+k_{13}$, $\alpha \beta=k_{21} \cdot k_{10}+k_{21} \cdot k_{13}$.

The rate constants $k_{13}$ and $k_{30}$ can be expressed as:

$$
\begin{aligned}
& k_{13}=\frac{\left(Q_{F}+Q_{D}\right) \cdot S C}{V_{1}} \\
& k_{30}=\frac{\left(Q_{F}+Q_{D}\right)}{V_{3}}
\end{aligned}
$$

Where $\mathrm{Q}_{\mathrm{F}}$ is the filtrate flow rate $(\mathrm{L} / \mathrm{hr}) ; \mathrm{Q}_{\mathrm{D}}$ is the dialysate flow rate $(\mathrm{L} / \mathrm{hr})$.
The clearance in $\mathrm{CHDF}\left(\mathrm{CL}_{\mathrm{CHDF}}\right)$ was calculated as $\left(\mathrm{Q}_{\mathrm{F}}+\mathrm{Q}_{\mathrm{D}}\right) \cdot \mathrm{SC}$ and the clearance by non-CHDF routes $\left(\mathrm{CL}_{\text {non-CHDF }}\right)$ was estimated as $k_{10} \cdot V_{1}$.

We modified the formula of Ikawa et al. [18] to include data obtained not only after the first administration of BIPM, but also those obtained during repeated administration of BIPM. The concentration-time data of BIPM in plasma and FD were concurrently fitted to the multi-compartment model described above.

Glomerular filtration rate (GFR) ( $\mathrm{mL} / \mathrm{min} /$ body) was calculated as follows:

$$
\begin{gathered}
\text { GFR }=\frac{e G F R \cdot B S A}{1.73} \\
\text { male }: e G F R=194 \cdot \mathrm{Scr}^{-1.094} \cdot \mathrm{Age}^{-0.287} \\
B S A=\frac{105.29 \cdot \mathrm{H} t^{0.619} \cdot B W^{0.460}}{10,000} \\
\text { female : eGFR }=194 \cdot \mathrm{Scr}^{-1.094} \cdot \mathrm{Age}^{-0.287} \cdot 0.739 \\
B S A=\frac{82.84 \cdot \mathrm{Ht}^{0.689} \cdot B \mathrm{~W}^{0.437}}{10,000}
\end{gathered}
$$

Where eGFR is estimated glomerular filtration rate $\left(\mathrm{mL} / \mathrm{min} / 1.73 \mathrm{~m}^{2}\right)$; BSA is body surface area $\left(\mathrm{m}^{2}\right)$ [20]; Scr is serum creatinine concentration $(\mathrm{mg} / \mathrm{dL})$; Age is given in years; $\mathrm{Ht}$ is height $(\mathrm{cm})$; $\mathrm{BW}$ is body weight $(\mathrm{kg})$. eGFR was determined just before CHDF application.

\section{Calculation of the PK/PD breakpoint by Monte Carlo simulation}

Monte Carlo simulation was performed with the normal random number generation function of Microsoft ${ }^{\ominus}$ Excel $^{\odot}$ 2007 (Microsoft, USA). We generated a population parameter set of 10,000 cases using a mean and variance of $k_{21}, V_{1}, \alpha$ and $\beta$ obtained by the standard two-stage method (compartmental analysis), thereby generating the BIPM plasma concentration transition of 10,000 cases. After setting the dosing interval and administration time of BIPM in the above formula $\left(C_{1}\right)$, the exposure time for which the BIPM plasma concentration remained at the MIC was finally calculated as the cumulative percentage over a $24 \mathrm{~h}$ period in the BIPM plasma concentration transition of the 10,000 cases [21-23]. Then, we calculated the number of cases that showed $\mathrm{T}>\mathrm{MIC}$ of $40 \%$ or more at each $\mathrm{PK} / \mathrm{PD}$ target value in each regimen. Maximum MIC of more than $80 \%$ was set as the PK/PD breakpoint probability of target attainment (PTA) in each regimen.

\section{Results}

In the present study, no adverse events or laboratory abnormalities were noted that were definitely attributable to BIPM. 
SC of the PS membrane was calculated to be $1.00 \pm$ 0.06 by non-compartmental analysis (Table 2). The PK parameters estimated by compartmental analysis were as follows: $V_{1}, 13.46 \pm 5.29 \mathrm{~L} ; k_{12}, 0.75 \pm 0.71 \mathrm{~h}^{-1} ; k_{21}, 0.95 \pm$ $0.27 \mathrm{~h}^{-1} ; k_{10}, 0.39 \pm 0.22 \mathrm{~h}^{-1} ;$ and $k_{13}, 0.13 \pm 0.04 \mathrm{~h}^{-1}$ (Table 3). Figure 2 shows typical fittings between the plasma and FD concentration time curves obtained by compartmental analysis and the real values in $\mathrm{Pt}$. A and Pt. B. Time courses of BIPM concentration in plasma and FD obtained by compartmental analysis in other patients also closely fitted the observed values. $\mathrm{CL}_{\mathrm{CHDF}}$ and $\mathrm{CL}_{\text {non-CHDF }}$ were estimated to be $1.53 \pm 0.10 \mathrm{~L} / \mathrm{h}$ and $4.86 \pm 2.50 \mathrm{~L} / \mathrm{h}$, respectively. The inter-individual variation in $\mathrm{CL}_{\text {non-CHDF }}$ was large. The sum of $\mathrm{CL}_{\mathrm{CDHF}}$ and $\mathrm{CL}_{\text {non-CHDF}}$ calculated as $\left(\mathrm{Q}_{\mathrm{F}}+\mathrm{Q}_{\mathrm{D}}\right) \cdot \mathrm{SC}$ and as $k_{10} \cdot V_{1}$, respectively $[\mathrm{x}]$, and $\mathrm{CL}_{\text {tot }}$ obtained by non-compartmental analysis of the plasma BIPM concentration [y] showed a good correlation $\left(y=1.01 \mathrm{x}-0.02, r^{2}=1.00\right)$, supporting the validity of the model. As shown in Fig. 3, the correlation between GFR obtained just before $\mathrm{CHDF}$ and $\mathrm{CL}_{\text {non-CHDF }}$ was also high $\left(r^{2}=0.97\right)$, and the slope and y-intercept were 1.86 and 1.02 , respectively. In this study, the number of patients who showed $\mathrm{T}>\mathrm{MIC}_{4 \mu \mathrm{g} / \mathrm{mL}}$ values of $40 \%$ or more was 6 , and one was in the range of 20 to $40 \%$. Moreover, the number of patients with $\mathrm{T}>\mathrm{MIC}_{8} \mu \mathrm{g} / \mathrm{mL}$ values of more than $40 \%$ was one, and 6 were in the range of 20 to $40 \%$.

Figure 4 shows $\%$ of $\mathrm{T}>\mathrm{MIC}$ values in plasma of patients undergoing CHDF based on the average parameters of the multi-compartment models on various regimens, including different values of infusion time, MIC values, sum of $\mathrm{Q}_{\mathrm{F}}$ and $\mathrm{Q}_{\mathrm{D}}$, dosage and administration. As $\mathrm{Q}_{\mathrm{F}}+\mathrm{Q}_{\mathrm{D}}$ increased, \% of $\mathrm{T}>\mathrm{MIC}$ slightly decreased. In addition, $\%$ of $\mathrm{T}>\mathrm{MIC}$ for $1 \mathrm{~h}$ infusion was higher than that for $0.5 \mathrm{~h}$ infusion under the same conditions of $\mathrm{Q}_{\mathrm{F}}+\mathrm{Q}_{\mathrm{D}}$ and administration dose. The most effective regimen was $300 \mathrm{mg}$ every $6 \mathrm{~h}$ given by $1 \mathrm{~h}$ infusion, with a $\mathrm{Q}_{F}+\mathrm{Q}_{\mathrm{D}}$ value of $1.5 \mathrm{~L} / \mathrm{h}$. This method could achieve $\%$ of $\mathrm{T}>\mathrm{MIC}$ of $82.8 \%$ at $\mathrm{MIC}=4 \mu \mathrm{g} / \mathrm{mL}$, and $35.1 \%$ at $\mathrm{MIC}=8 \mu \mathrm{g} / \mathrm{mL}$.

Based on Monte Carlo simulation of the case of $0.5 \mathrm{~h}$ infusion, the PK/PD breakpoint was $0.5 \mu \mathrm{g} / \mathrm{mL}$ in the regimen of dosage $300 \mathrm{mg}$ every $12 \mathrm{~h}$, and was $1.0 \mu \mathrm{g} /$ $\mathrm{mL}$ in the regimens of dosage $300 \mathrm{mg}$ every $8 \mathrm{~h}$, dosage $300 \mathrm{mg}$ every $6 \mathrm{~h}$, and dosage $600 \mathrm{mg}$ every $12 \mathrm{~h}$ (Fig. 5). In the case of $1 \mathrm{~h}$ infusion, the PK/PD breakpoint was $1.0 \mu \mathrm{g} / \mathrm{mL}$ in the regimen of dosage $300 \mathrm{mg}$ every $12 \mathrm{~h}$, and $2.0 \mu \mathrm{g} / \mathrm{mL}$ in the regimens of dosage $300 \mathrm{mg}$ every $8 \mathrm{~h}$, dosage $300 \mathrm{mg}$ every $6 \mathrm{~h}$, and dosage $600 \mathrm{mg}$ every $12 \mathrm{~h}$. The PTAs were greater for $1 \mathrm{~h}$ infusion than for $0.5 \mathrm{~h}$ infusion in all cases. Among them, PTA of the regimen of dosage $300 \mathrm{mg}$ every $6 \mathrm{~h}$ showed the highest value $(90.2 \%)$. The Japan Society of Chemotherapy defines the clinical breakpoint as more than $80 \%$, though more than $90 \%$ of the PTA has become a reference value of the PK/PD breakpoint outside of Japan.

\section{Discussion}

In this study, we investigated the PK of BIPM using compartmental and non-compartmental analysis in patients undergoing CHDF who had various levels of renal function, and examined the suitability of various administration regimens in terms of $\mathrm{PK} / \mathrm{PD}$ breakpoint for various bacteria, by means of Monte Carlo simulation.

Ikawa et al. analyzed time courses of BIPM concentration in plasma and FD after single administration in renal failure patients undergoing CHDF [18]. Here, we aimed to obtain a model to analyze the results of repeated administration of BIPM in patients undergoing CHDF who retained various levels of renal function. Time courses of BIPM concentration in plasma and FD in patients undergoing CHDF closely fitted the observed values, suggesting that the constructed model formula

Table 2 Pharmacokinetic parameters calculated by non-compartmental analysis

\begin{tabular}{|c|c|c|c|c|c|c|c|c|c|}
\hline Patient & $\begin{array}{l}A \cup C_{0 \rightarrow \text { r, plasma }} \\
(\mathrm{mg} \cdot \mathrm{hr} / \mathrm{L})\end{array}$ & $\begin{array}{l}A \cup C_{0 \rightarrow \tau, \text { FD }} \\
(\mathrm{mg} \cdot \mathrm{hr} / \mathrm{L})\end{array}$ & SC & $\begin{array}{l}\mathrm{CL}_{\text {tot }} \\
(\mathrm{L} / \mathrm{hr}) \\
\end{array}$ & $\begin{array}{l}V d_{s s} \\
(L) \\
\end{array}$ & $\begin{array}{l}C_{\text {max, plasma }} \\
(\mu \mathrm{g} / \mathrm{mL})\end{array}$ & $\begin{array}{l}C_{\max , F D} \\
(\mu \mathrm{g} / \mathrm{mL})\end{array}$ & $\begin{array}{l}\mathrm{T}_{1 / 2, \text { plasma }} \\
(\mathrm{hr})\end{array}$ & $\begin{array}{l}\mathrm{T}_{1 / 2, \mathrm{FD}} \\
(\mathrm{hr})\end{array}$ \\
\hline A & 37.7 & 37.6 & 1.00 & 7.96 & 0.33 & 11.92 & 11.29 & 3.99 & 3.20 \\
\hline B & $72.4^{\mathrm{a}}$ & $79.7^{\mathrm{a}}$ & 1.10 & 4.14 & 0.46 & 15.93 & 12.09 & 3.97 & 5.43 \\
\hline C & 63.2 & 61.2 & 0.97 & 4.75 & 0.30 & 20.08 & 19.43 & 3.42 & 3.62 \\
\hline D & 31.4 & 29.9 & 0.95 & 9.54 & 0.35 & 12.15 & 9.13 & 2.05 & 2.20 \\
\hline$E$ & 54.3 & 55.3 & 1.02 & 5.53 & 0.33 & 19.42 & 19.55 & 2.83 & 2.73 \\
\hline$F$ & 32.2 & 29.9 & 0.93 & 9.32 & 0.24 & 23.93 & 15.37 & 1.38 & 1.25 \\
\hline G & 78.2 & 79.6 & 1.02 & 3.84 & 0.17 & 25.80 & 24.24 & 3.39 & 3.66 \\
\hline Mean & & & 1.00 & 6.44 & 0.31 & & & 3.00 & 3.15 \\
\hline SD & & & 0.06 & 2.45 & 0.09 & & & 0.99 & 1.31 \\
\hline
\end{tabular}

$A \cup C_{O \rightarrow \tau, \text { plasma }}$ area under the plasma concentration-time curve from time 0 to next infusion; $A U C_{O \rightarrow \tau,} F D$ area under the filtrate-dialysate concentration-time curve from time 0 to next infusion; $S C$ sieving coefficient $\left(A U C_{0 \rightarrow \mathrm{r}, \mathrm{FD}} / A U C_{0 \rightarrow \mathrm{T}}\right.$, Plasma); $C L_{\text {tot }}$ total clearance ( $300 / A U C_{0 \rightarrow \tau}$, plasma); $V d_{s s}$ volume of distribution at the steady state; $C_{\text {max,plasma }}$ maximum concentration of BIPM in plasma; $C_{\max }$, FD maximum concentration of BIPM in filtrate-dialysate; $T_{1 / 2,}$, plasma elimination half-life of BIPM in plasma; $T_{1 / 2, F D}$ elimination half-life of BIPM in filtrate-dialysate; $S D$ standard deviation

${ }^{\mathrm{a} A U C_{0 \rightarrow \infty}}$ 
Table 3 Pharmacokinetic parameters of biapenem after intravenous administration of biapenem (300 mg) during CHDF

\begin{tabular}{|c|c|c|c|c|c|c|c|}
\hline Patient & $V_{1}(\mathrm{~L})$ & $k_{12}\left(\mathrm{hr}^{-1}\right)$ & $k_{21}\left(\mathrm{hr}^{-1}\right)$ & $k_{10}\left(\mathrm{hr}^{-1}\right)$ & $k_{13}\left(\mathrm{hr}^{-1}\right)$ & $\mathrm{CL}_{\mathrm{CHDF}}(\mathrm{L} / \mathrm{hr})$ & $\mathrm{CL}_{\text {non-CHDF }}(\mathrm{L} / \mathrm{hr})$ \\
\hline A & 11.09 & 2.26 & 1.10 & 0.56 & 0.14 & 1.53 & 6.24 \\
\hline B & 17.45 & 0.33 & 0.66 & 0.15 & 0.09 & 1.65 & 2.54 \\
\hline C & 9.51 & 0.74 & 0.92 & 0.33 & 0.16 & 1.55 & 3.11 \\
\hline D & 23.84 & 0.18 & 1.13 & 0.34 & 0.06 & 1.43 & 8.04 \\
\hline E & 11.74 & 0.26 & 0.51 & 0.33 & 0.14 & 1.63 & 3.93 \\
\hline $\mathrm{F}$ & 10.19 & 0.69 & 1.08 & 0.78 & 0.14 & 1.39 & 7.92 \\
\hline G & 10.43 & 0.79 & 1.25 & 0.22 & 0.15 & 1.53 & 2.27 \\
\hline Mean & 13.46 & 0.75 & 0.95 & 0.39 & 0.13 & 1.53 & 4.86 \\
\hline SD & 5.29 & 0.71 & 0.27 & 0.22 & 0.04 & 0.10 & 2.50 \\
\hline
\end{tabular}

$V_{1}$ Volume of distribution of central compartment; $k_{12}$ transfer rate constant from central compartment to peripheral compartment; $k_{21}$ transfer rate constant from peripheral compartment to central compartment; $k_{10}$ elimination rate constant from central compartment; $k_{13}$ transfer rate constant from central compartment to filtrate-dialysate side compartment $\left(\mathrm{Q}_{\mathrm{F}}+\mathrm{Q}_{\mathrm{D}}\right) \cdot \mathrm{SC} / V_{1} ; C L_{C H D F}$ clearance by $C H D F\left(\mathrm{Q}_{\mathrm{F}}+\mathrm{Q}_{\mathrm{D}}\right) \cdot \mathrm{SC} ; C L_{\text {non-CHDF }}$ clearance by non-CHDF routes $\left(k_{10} \cdot V_{1}\right) ; S D$ standard deviation

successfully represents the results of repeated administration of BIPM in patients undergoing CHDF. In the present study, SC (indicating penetration from blood to dialyzer) was almost 1.0 for the PS membrane material, which is almost the same as the value for PMMA membrane $[18,24]$. Thus, there appears to be essentially no difference between PS and PMMA membranes in regard to drug penetration [18]. These results seem consistent with the characteristics of BIPM, such as low molecular weight and low protein binding rate.

We found a strong correlation between the sum of $\mathrm{CL}_{\text {non-CHDF }}$ and $\mathrm{CL}_{\mathrm{CHDF}}$ obtained by compartmental analysis and total clearance obtained by non-compartmental analysis $\left(r^{2}=1.00\right)$, indicating that the compartment model formula was appropriate. Ikawa et al. reported that $\mathrm{CL}_{\mathrm{CHDF}}(1.29 \pm 0.08 \mathrm{~L} / \mathrm{h})$ was almost the same as the sum of $\mathrm{Q}_{\mathrm{F}}$ and $\mathrm{Q}_{\mathrm{D}}(1.4 \mathrm{~L} / \mathrm{h})$ in CHDF with a PMMA membrane [18]. Suyama et al. also reported that $\mathrm{CL}_{\mathrm{CHDF}}$
$(1.28 \pm 0.14 \mathrm{~L} / \mathrm{h})$ was almost the same as the sum of $\mathrm{Q}_{\mathrm{F}}$ and $\mathrm{Q}_{\mathrm{D}}(1.4 \mathrm{~L} / \mathrm{h})$ in CHDF with a PMMA membrane [24]. In this study, $\mathrm{CL}_{\mathrm{CHDF}}(1.5 \pm 0.1 \mathrm{~L} / \mathrm{h})$ estimated by compartmental analysis was similar to the sum of $\mathrm{Q}_{\mathrm{F}}$ and $\mathrm{Q}_{\mathrm{D}}$ $(1.5-1.7 \mathrm{~L} / \mathrm{h})$ in CHDF with a PS membrane. Considering the $\mathrm{SC}$ estimated by non-compartmental analysis, $\mathrm{CL}_{\mathrm{CHDF}}$ of BIPM would be determined by the sum of dialysate flow rate and filtration flow rate. On the other hand, $\mathrm{CL}_{\text {non-CHDF }}$ represents the sum of non-renal clearance and residual renal clearance. Metabolism of BIPM in kidney and other

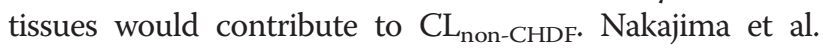
detected two DHP-1 metabolites of BIPM, L-cysteine and L-cystine, in urine, and reported that excretion of urinary metabolites accounted for approximately $15 \%$ of total clearance; these metabolites were not detected in plasma, suggesting that metabolism of BIPM in kidney contributes to residual renal clearance [19]. DHP-1 is also expressed in the ascending colon and ileum as well as the kidney, and

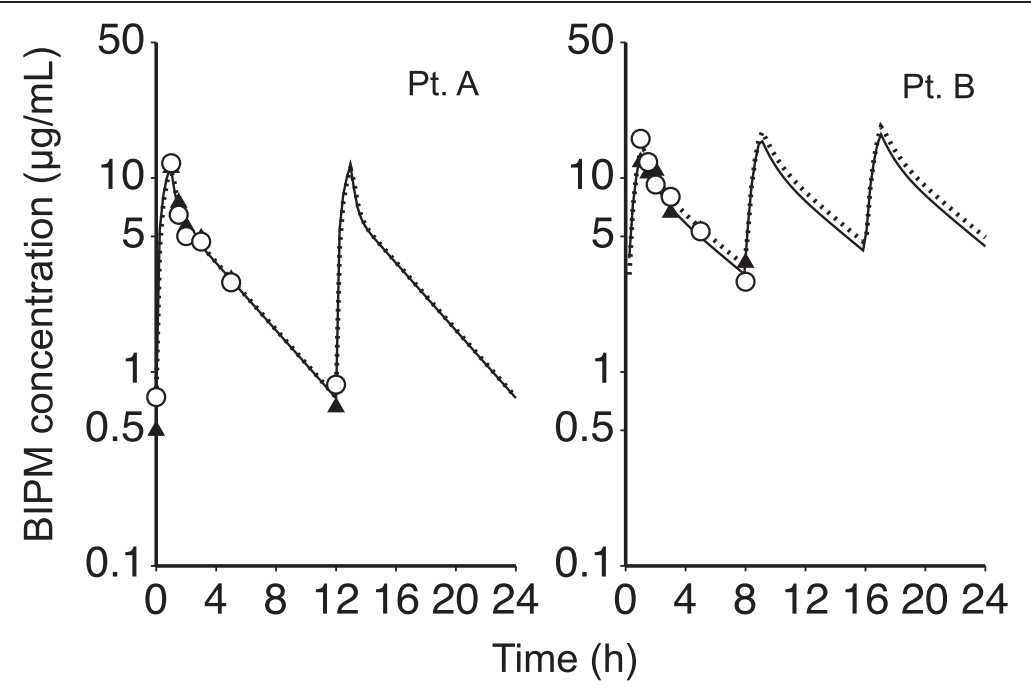

Fig. 2 Typical fittings between the plasma and FD concentration simulation curves and the observed values. Simulation curves of plasma (open circles, solid line) and FD (closed triangle, dotted line) concentration were obtained by compartmental analysis 


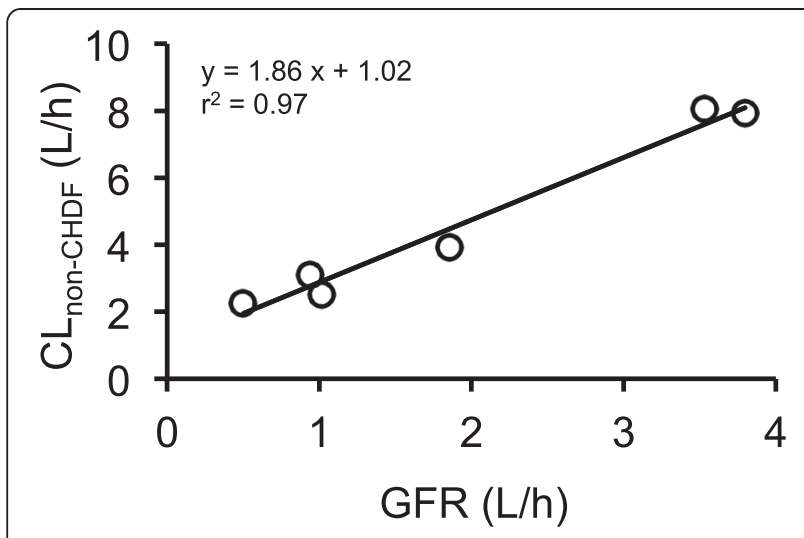

Fig. 3 Correlation between individual GFR and $C L_{\text {non-CHDF. The solid }}$ line indicates the linear regression line

the activity of DHP-1 in ileum has been reported to be twice that in kidney, suggesting that non-renal DHP-1 function in ileum would also contribute to non-renal clearance [25]. The relationship between GFR calculated before CHDF application and $\mathrm{CL}_{\text {non-CHDF }}$ was given by $y=1.86$ $\mathrm{x}+1.02\left(r^{2}=0.97\right)($ Fig. 3$)$, and the $y$-intercept $(1.02 \mathrm{~L} / \mathrm{h})$ represents non-renal clearance. Non-renal clearance in healthy adults can be estimated as approximately $3.23 \mathrm{~L} / \mathrm{h}$, using reported values of total clearance of BIPM in healthy adults of $12.9 \pm 1.2 \mathrm{~L} / \mathrm{h}$, and urinary excretion rates of unchanged and changed BIPM of approximately 60 and $15 \%$, respectively [19]. Nagashima et al. reported that non-renal clearance was $2.60 \pm 1.55 \mathrm{~L} / \mathrm{h}$ in patients with renal failure during dialysis with a PS membrane, while $\mathrm{CL}_{\text {tot }}$ in patients was $2.62 \pm 0.60 \mathrm{~L} / \mathrm{h}$ without $\mathrm{HD}$, so that
$\mathrm{CL}_{\text {tot }}$ was the same as non-renal clearance in patients with renal failure [17]. Non-renal clearance in the present study was a half to one-third of those values. After extracting patients with sepsis from Fig. 3, the y-intercept took a negative value (data not shown), indicating that non-renal clearance would be almost zero in patients with sepsis. In sepsis, hepatic clearance and renal clearance would be diminished owing to the reduced function of systemic organs and impaired blood flow [26], leading to loss of DHP-1 activity in the kidney and other organs. Thus, we consider that the reason why average non-renal clearance in this study was lower than in previous studies is the low values in patients with sepsis.

We investigated the variation in $\%$ of $\mathrm{T}>\mathrm{MIC}$ based on the average values of the PK parameters obtained by compartmental analysis for different regimens, including dose, dosing interval, infusion time, and CHDF conditions applied in our hospital. The \% of $\mathrm{T}>\mathrm{MIC}_{4} \mu \mathrm{g} / \mathrm{mL}$ was more than $40 \%$ in all regimens of $900 \mathrm{mg}$ or more daily dose, regardless of the CHDF conditions and infusion time. Ikawa et al. also reported that although the regimen of $300 \mathrm{mg}$ every $12 \mathrm{~h}$ failed to achieve $\mathrm{T}>\mathrm{MIC}_{4} \mu \mathrm{g} / \mathrm{mL}$ of more than $40 \%$, the regimen of $600 \mathrm{mg}$ every $12 \mathrm{~h}$ did do so [18]. These results indicate that the minimum dosage regimen required to achieve $\mathrm{T}>\mathrm{MIC}_{4 \mu \mathrm{g} / \mathrm{mL}}$ of more than $40 \%$ is $300 \mathrm{mg}$ every 8 h (total amount: $900 \mathrm{mg}$ ). On the other hand, no regimen gave $\%$ of $\mathrm{T}>\mathrm{MIC}_{8} \mu \mathrm{g} / \mathrm{mL}$ of more than $40 \%$, suggesting that these regimens could not achieve the maximal kill end point. However, since the $\%$ of $\mathrm{T}>\mathrm{MIC}$ values obtained using average PK parameters do not reflect variations of $\mathrm{CL}_{\text {non-CHDF }}$ associated with partial

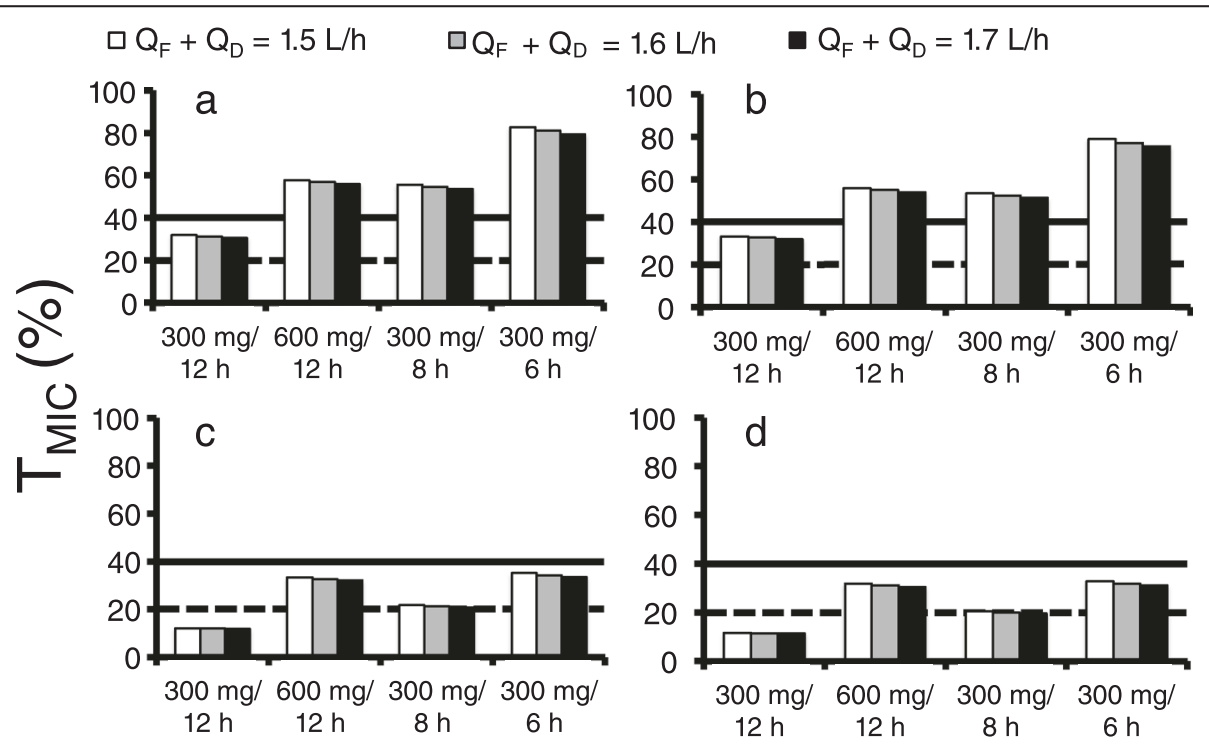

Fig. 4 Values of $\mathrm{T}>\mathrm{MIC}$ of $4 \mu \mathrm{g} / \mathrm{mL}$ and $8 \mu \mathrm{g} / \mathrm{mL}$ in different regimens. Panel a represents the case of $\mathrm{MIC}=4 \mu \mathrm{g} / \mathrm{mL}$ and infusion time $1 \mathrm{~h}$; Panel $\mathbf{b}$ represents the case of $\mathrm{MIC}=4 \mu \mathrm{g} / \mathrm{mL}$ and infusion time $0.5 \mathrm{~h}$; Panel $\mathbf{c}$ represents the case of MIC = $8 \mu \mathrm{g} / \mathrm{mL}$ and infusion time $1 \mathrm{~h}$; Panel $\mathbf{d}$ represents the case of $\mathrm{MIC}=8 \mu \mathrm{g} / \mathrm{mL}$ and infusion time $0.5 \mathrm{~h}$. The solid line represents $40 \% \mathrm{~T}>\mathrm{MIC}$. The dotted line represents $20 \% \mathrm{~T}>\mathrm{MIC}$ 


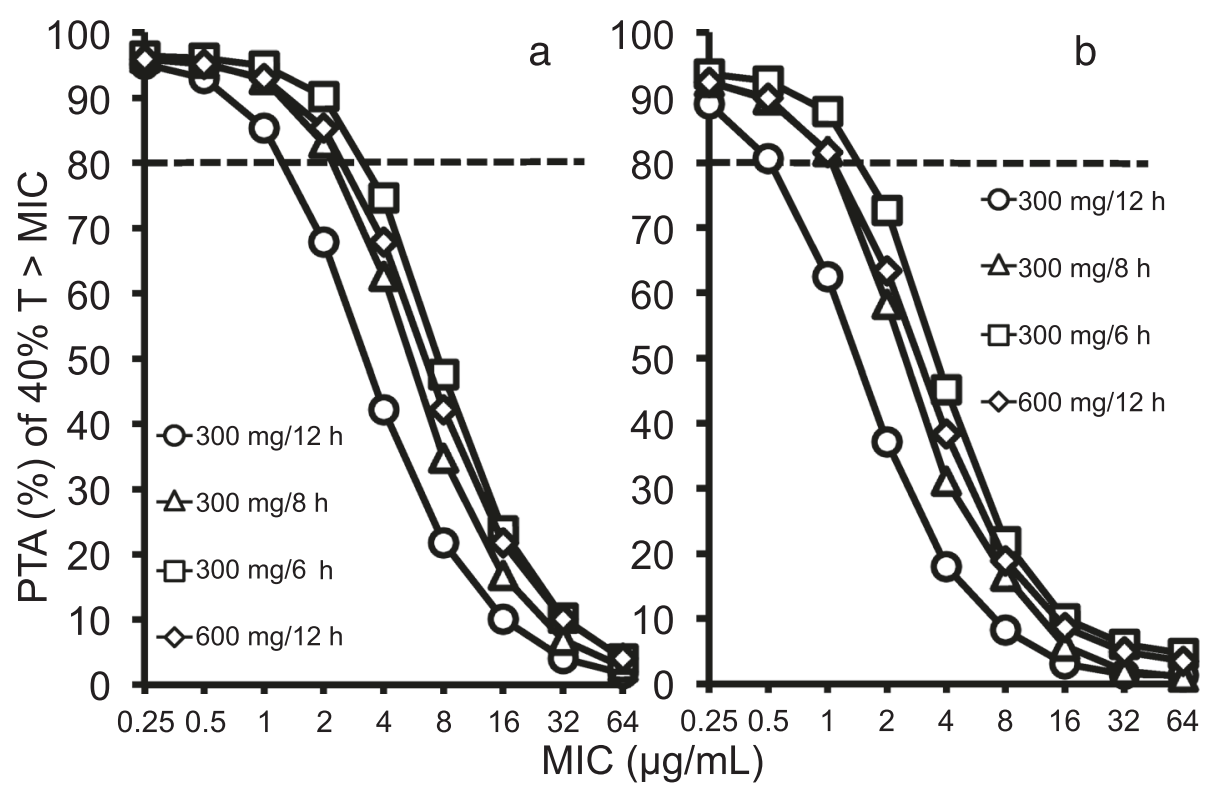

Fig. 5 PTA of $40 \%$ T > MIC in plasma at specific MICs for different BIPM regimens. The dotted line represents $80 \%$ PTA. Panel a: infusion time of $1 \mathrm{~h}$; Panel $\mathbf{b}$ : infusion time of $0.5 \mathrm{~h}$

kidney function, these values may not be adequate as a clinical indicator.

Monte Carlo simulation is a computer modeling process that incorporates variability in pharmacokinetic parameters and the natural MIC distribution within a bacterial population. It can be used to develop interpretive susceptibility criteria based on PK/PD breakpoints [27]. In this study, Monte Carlo simulations with 10,000 cases were performed to examine PK/PD breakpoint using the mean and variance of the PK parameters. As regards infusion time, the PK/PD breakpoint obtained for all regimens with $1 \mathrm{~h}$ infusion was higher than that for $0.5 \mathrm{~h}$ infusion, suggesting that the $1 \mathrm{~h}$ infusion provides a better outcome. In this study, the highest PK/PD breakpoint (over $80 \%$ PTA) was $2 \mu \mathrm{g} / \mathrm{mL}$ with $300 \mathrm{mg}$ every $8 \mathrm{~h}, 300 \mathrm{mg}$ every $6 \mathrm{~h}$, and $600 \mathrm{mg}$ every $12 \mathrm{~h}$, indicating that these regimens provide a sufficient bactericidal effect in the case of bacteria with $\mathrm{MIC}_{2 \mu \mathrm{g} / \mathrm{mL}}$, but not $\mathrm{MIC}_{4} \mu \mathrm{g} / \mathrm{mL}$. In order to obtain an antimicrobial effect of BIPM towards high MIC bacteria (more than $4 \mu \mathrm{g} / \mathrm{mL}$ ), such as Pseudomonas aeruginosa, higher dose administration and an appropriate regimen would be needed, although the maximum permitted dose of BIPM in Japan has been set at 1,200 mg/day. Among the regimens examined in this study, $300 \mathrm{mg}$ every $6 \mathrm{~h}$ with infusion for $1 \mathrm{~h}$ was the optimal regimen, and PTA at $\mathrm{MIC}_{2} \mu \mathrm{g} / \mathrm{mL}$ was $90.2 \%$. Although maximum MIC more than $80 \%$ is adopted as the PK/PD breakpoint in Japan, most other countries define it as more than $90 \%$ [27], so the regimen of $300 \mathrm{mg}$ every $6 \mathrm{~h}$ with infusion for $1 \mathrm{~h}$ also meets the international standard for $\mathrm{MIC}_{2} \mu \mathrm{g} / \mathrm{mL}$ bacteria. Although the PK/PD breakpoint is expected to become a decision criterion for individualized and optimized antibacterial therapy, it is focused primarily on the antibacterial agent. In the future, it will be important to take bacterial character into account as well, for example, by means of antimicrobial susceptibility testing and identification of the causative bacteria of infectious diseases.

The present study has several limitations. Firstly, we performed the Monte Carlo simulation using the mean and variance of the PK parameters obtained with the standard two-stage method because of the small number of cases (total, 7 cases), and this might have resulted in overestimation of the inter-individual variation compared to population pharmacokinetics analysis, such as nonlinear mixed effects modelling $\left(\mathrm{NONMEM}^{\circ}\right)$. Further, we did not include a parameter of renal function (e.g. GFR or creatinine clearance) in the Monte Carlo simulation, even though BIPM clearance is correlated with renal function. Therefore, as a next step, it would be desirable to identify the PK/PD breakpoint more precisely in patients undergoing CHDF by means of Monte Carlo simulation of BIPM using population pharmacokinetic parameters including renal function (e.g. GFR and creatinine clearance), based on larger numbers of patients with various levels of renal function. In addition, from the viewpoint of clinical applicability, we did not establish that the optimal regimen (300 mg every $6 \mathrm{~h}$ with infusion for $1 \mathrm{~h}$ ) determined by Monte Carlo simulation is safe, because only one patient received the optimal regimen in this study. Therefore, it is impossible to evaluate the safety of optimal regimen. However, the simulated maximum steady-state plasma concentration 
with the optimal regimen in the present study was approximately $11-24 \mu \mathrm{g} / \mathrm{mL}$. This concentration is lower than the maximum steady-state plasma concentration after administration of $600 \mathrm{mg}$ by $1 \mathrm{~h}$ infusion every $12 \mathrm{~h}$ in healthy adults $(32.4 \pm 2.32 \mu \mathrm{g} / \mathrm{mL})$ [19]. Therefore, it seems likely that the optimal regimen would be safe even in renal dysfunction patients undergoing CHDF. Nevertheless, it will be important to confirm the safety of the optimal regimen, and clinicians should carefully consider the appropriate regimen when administering BIPM to renal dysfunction patients undergoing CHDF, in addition to monitoring for side effects.

\section{Conclusions}

In the present study, we used PK modeling to establish the optimal regimen of BIPM in patients with various levels of renal function undergoing CHDF. Clearance of CHDF was determined by the flow rate of dialysate and filtration conditions, since almost BIPM flowed into the dialyzer. The results of Monte Carlo simulation indicated that the regimen of $300 \mathrm{mg}$ every $6 \mathrm{~h}$ infusion for $1 \mathrm{~h}$ was optimal, compared to other regimens used in our hospital. This regimen showed effective antibacterial activity towards $\mathrm{MIC}_{2} \mu \mathrm{g} / \mathrm{mL}$ bacteria.

\begin{abstract}
Abbreviations
CHDF: Continuous hemodiafiltration; PK: Pharmacokinetics; BIPM: Biapenem; DHP-1: Dehydropeptidase-1; MIC: Minimum inhibitory concentration; T > MIC: Time above the MIC; PMMA: Polymethyl methacrylate; PS: Polysulfone; GFR: Glomerular filtration rate; $Q_{B}$ : Blood flow rate; $Q_{D}$ : Dialysate flow rate; $\mathrm{Q}_{S}$ : Substitution flow rate; $\mathrm{Q}_{\mathrm{F}}$ : Filtration flow rate; FD: Filtrate-dialysate; SC: Sieving coefficient; HPLC: High-performance liquid chromatography; Napp: Numeric Analysis Program for Pharmacokinetics; AUC: Area under the concentration-time curve; PTA: Probability of target attainment.
\end{abstract}

\section{Competing interests}

This study was supported in part by Meiji Seika Pharma Co. Ltd.

\section{Authors' contributions}

GA collected samples, performed experiments (HPLC), analyzed data, and drafted the manuscript. YH performed experiments (HPLC) and analyzed data. KI collected samples and analyzed data. KS and KM analyzed data. TS analyzed data, and helped to draft the manuscript. TN designed and coordinated the study, and collected samples. $T$ designed and coordinated the study. YS designed and coordinated the study, and helped to draft the manuscript. All authors read and approved the final manuscript.

\section{Acknowledgements}

This work was supported in part by JSPS KAKENHI Grants No. 23590173 and in part by a grant from Meiji Seika Pharma Co., Ltd.

\footnotetext{
Author details

'Department of Medicinal Informatics, Graduate School of Medical Sciences, Kanazawa University, 13-1 Takara-machi, Kanazawa 920-8640, Japan. ${ }^{2}$ Department of Hospital Pharmacy, University Hospital, Kanazawa University, 13-1 Takara-machi, Kanazawa 920-8641, Japan. ${ }^{3}$ School of Pharmacy, College of Medical, Pharmaceutical and Health Sciences, Kanazawa University, Kakuma-machi, Kanazawa, 920-1192, Japan. ${ }^{4}$ Intensive Care Unit, University Hospital, Kanazawa University, 13-1 Takara-machi, Kanazawa, 920-8641, Japan.
}

Received: 12 June 2015 Accepted: 23 October 2015

Published online: 14 November 2015

\section{References}

1. Murray P, Hall J. Renal replacement therapy for acute renal failure. Am J Respir Crit Care Med. 2000;162:777-81.

2. Matsuda K, Hirasawa H, Oda S, Shiga H, Nakanishi K. Current topics on cytokine removal technologies. Ther Apher. 2001;5:306-14.

3. Sadahiro T, Hirasawa H, Oda S, Shiga H, Nakanishi K, Kitamura N, et al. Usefulness of plasma exchange plus continuous hemodiafiltration to reduce adverse effects associated with plasma exchange in patients with acute liver failure. Crit Care Med. 2001;29:1386-92.

4. Jiang HL, Xue WJ, Li DQ, Yin AP, Xin X, Li CM, et al. Influence of continuous veno-venous hemofiltration on the course of acute pancreatitis. World J Gastroenterol. 2005;11:4815-21.

5. Hirasawa H. Indications for blood purification in critical care. Contrib Nephol. 2010;166:21-30.

6. Oda S, Sadahiro T, Hirayama Y, Nakamura M, Watanabe E, Tateishi Y, et al. Non-renal indications for continuous renal replacement therapy: Current status in Japan. Contrib Nephol. 2010;166:47-53.

7. Trotman RL, Williamson JC, Shoemaker DM, Salzer WL. Antibiotic dosing in critically ill adult patients receiving continuous renal replacement therapy. Clin Infect Dis. 2005;41:1159-66.

8. Hidaka S, Goto K, Hagiwara S, Iwasaka H, Noguchi T. Doripenem pharmacokinetics in critically ill patients receiving continuous hemodiafiltration. Yakugaku Zasshi. 2010;130:87-94.

9. Pollard TA, Lampasona V, Akkerman S, Tom K, Hooks MA, Mullins RE, et al. Vancomycin redistribution: dosing recommendations following high-flux hemodialysis. Kidney Int. 1994;45:232-7.

10. Ubukata K, Hikida M, Yoshida M, Nishiki K, Furukawa Y, Tashiro K, et al. In vitro activity of LJC10,627, a new carbapenem antibiotic with high stability to dehydropeptidase I. Antimicrob Agents Chemother. 1990;34:994-1000.

11. Hikida M, Kawashima K, Nishiki K, Furukawa Y, Nishizawa K, Saito I, et al. Renal dehydropeptidase-I stability of LJC 10,627, a new carbapenem antibiotic. Antimicrob Agents Chemother. 1992;36:481-3.

12. Yang Y, Testa RT, Bhachech N, Rasmussen BA, Bush K. Biochemical characterization of novel tetrahydrofuranyl $1 \beta$-methylcarbapenems: Stability to hydrolysis by renal dehydropeptidases and bacterial $\beta$-lactamases, Binding to penicillin binding proteins, and permeability properties. Antimicrob Agents Chemother. 1999:43:2904-9.

13. Fukasawa M, Sumita Y, Harabe ET, Tanio T, Nouda H, Kohzuki T, et al Stability of meropenem and effect of $1 \beta$-methyl substitution on its stability in the presence of renal dehydropeptidase I. Antimicrob Agents Chemother. 1992;36:1577-9.

14. Craig WA. Pharmacokinetic/pharmacodynamics parameters: rationale for antibacterial dosing mice and men. Clin Infect Dis. 1998;26:1-12.

15. Drusano GL. Prevention of resistance: a goal for dose selection for antimicrobial agents. Clin Infect Dis. 2003;36:S42-50.

16. Clinical and laboratory standards institute. Performance standard for antimicrobial susceptibility testing; Twenty-second informational supplement. M100-S22. Wayne: Clinical and Laboratory Standards Institute; 2012. p. 1-184.

17. Nagashima S, Kozawa O, Otsuka T, Kohno K, Minamoto M, Yokokawa M, et al. Pharmacokinetics of a parenteral carbapenem, biapenem, in patients with end-stage renal disease and influence of hemodialysis. J Antimicrob Chemother. 2000;46:839-42.

18. Ikawa K, Morikawa N, Ikeda K, Suyama H. Pharmacokinetic modeling and dosage adaptation of biapenem in Japanese patients during continuous venovenous hemodiafiltration. J Infect Chemother. 2008;14:35-9.

19. Nakajima M, Uematsu T, Ueno K, Watanabe K, Nagashima S, Inaba H, et al. Phase 1 study of L-627, biapenem, a new parenteral carbapenem antibiotic. Jpn Pharmacol Ther. 1994;22:255-71.

20. Shitara K, Takai M, Ohta M, Wakahara T, Kanehisa H, Fukunaga T, et al. Development of an equation for predicting body surface area based on three-dimensional photonic image scanning. Jpn J Phys Fitness Sports Med. 2009;58:463-74.

21. Ikawa K, Morikawa N, Ikeda K, Ohge H, Sueda T. Development of breakpoints of cephems for intraabdominal infections based on pharmacokinetics and pharmacodynamics in the peritoneal fluid of patients. J Infect Chemother. 2008;14:141-6.

22. Kuti JL, Dandekar PK, Nightingale CH, Nicolau DP. Use of Monte Carlo simulation to design an optimized pharmacodynamic dosing strategy for meropenem. J Clin Pharmacol. 2003;43:1116-23. 
23. Mouton JW, Dudley MN, Cars O, Derendorf H, Drusano GL. Standardization of pharmacokinetic/pharmacodynamic (PK/PD) terminology for anti-infective drugs: an update. J Antimicrob Chemother. 2005;55:601-7.

24. Suyama H, Ikawa K, Morikawa N, Ikeda K, Fujiue Y, Morikawa S, et al. Pharmacokinetics and pharmacodynamics of biapenem in critically ill patients under continuous venovenous hemodiafiltration. Jpn J Antibiot. 2008:61:303-13.

25. Murakami K. Experimental study of localization of dehydropeptidase-1 in human tissues and hydrolysis of carbapenems. J Wakayama Med Soc. 1993:44:601-15.

26. De Paepe P, Belpaire FM, Buylaert WA. Pharmacokinetic and pharmacodynamic considerations when treating patients with sepsis and septic shock. Clin Pharmacokinet. 2002:41:1135-51.

27. Frei $C R$, Wiederhold NP, Burgess DS. Antimicrobial breakpoints for gram-negative aerobic bacteria based on pharmacokinetic-

pharmacodynamic models with Monte Carlo simulation. J Antimicrob Chemother. 2008:61:621-8.

\section{Submit your next manuscript to BioMed Central and take full advantage of:}

- Convenient online submission

- Thorough peer review

- No space constraints or color figure charges

- Immediate publication on acceptance

- Inclusion in PubMed, CAS, Scopus and Google Scholar

- Research which is freely available for redistribution 